\title{
Por que o Brasil pode ser um dos primeiros países a sair da recessão?
}

\author{
Luciano Luiz Manarin D’Agostini*
}

RESUMO - Observa-se tanto em países desenvolvidos como em desenvolvimento quedas generalizadas do crescimento do PIB, da inflação e das taxas de juros. No contexto da crise financeira global, ao comparar indicadores macroeconômicos e expectativas de mercado doméstico e internacional, mostra-se, no texto, por que o Brasil pode ser um dos primeiros países a sair da recessão. Além disso, mostram-se as previsões, por modelos VAR, da taxa de juros, PIB e inflação para os próximos períodos.

Palavras-chave: Expectativas de mercado. Crise de liquidez.

Segundo Meirelles (2009) e Mesquita (2009), o Brasil poderá ser um dos primeiros países a sair da recessão. Para concordar com as autoridades monetárias e ter alguns argumentos para essa defesa observamos alguns indicadores macroeconômicos internos que tiveram sensível melhora nos últimos anos: indicadores de inflação comparado com suas respectivas metas e expectativas (Figura 1); nível da produção industrial (Figura 2); comparação do nível de queda da produção industrial e inflação acumulada entre países selecionados (Tabela 1); saldo da dívida líquida do setor público em relação ao PIB (Figura 3); a composição da dívida do setor público (Figura 4); a dívida externa com relação ao PIB (Figura 5) e a composição das reservas internacionais (Figura 6).

A inflação, medida pelo IPCA, desde 2003, apresenta-se comportada e dentro da meta pré-estabelecida, exceção no fim de 2004 e começo de 2005. No mais, para 2009, segundo Boletim Focus, temos expectativas de mercado de 4,33\% a.a, portanto entre o centro, $4,5 \%$ a.a, e o limite inferior da meta, $2,5 \%$.

Quanto ao nível de atividade, percebe-se grande queda verificada nos últimos meses (Figura 2), em decorrência da crise financeira. Ambos, inflação abaixo da meta e queda no nível de atividade aumentam as chances do COPOM (Comitê de Política Monetária) continuar o ciclo

\footnotetext{
* Doutorando em Desenvolvimento Econômico da Universidade Federal do Paraná. Endereço eletrônico: lucianodagostini@hotmail.com.
} 
FIGURA 1- IPCA OBSERVADO E A META DE INFLAÇÃO.

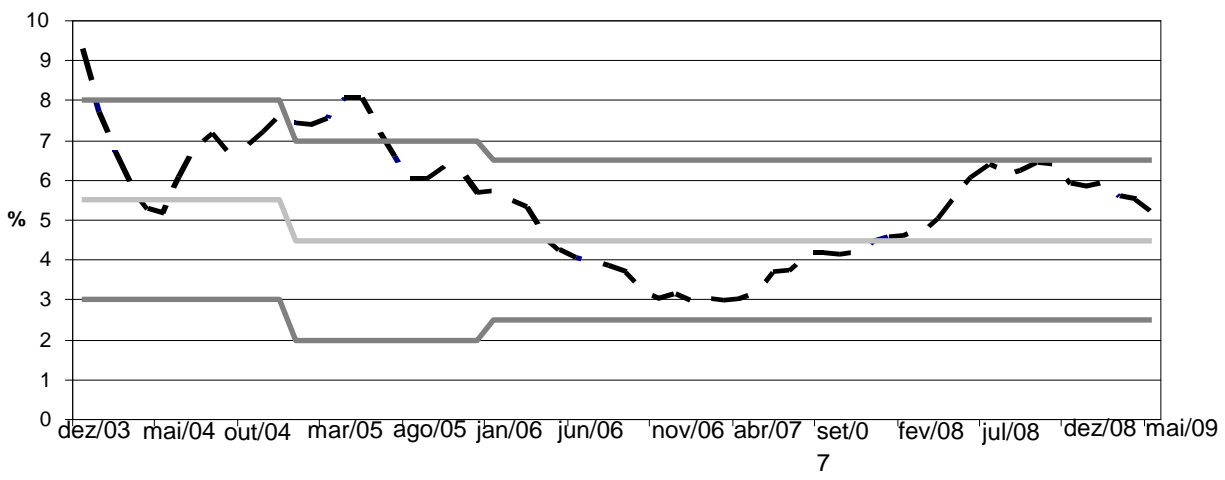

- Inflação Acum $\quad$ META Limite Inferior — Limite Superior

FONTE: Banco Central do Brasil.

de redução da SELIC caso exista reestruturação da rentabilidade da caderneta de poupança e alteração das LFT's ${ }^{23}$.

FIGURA 2 - PRODUÇÃO INDUSTRIAL - BRASIL, BASE=100 EM 2002.

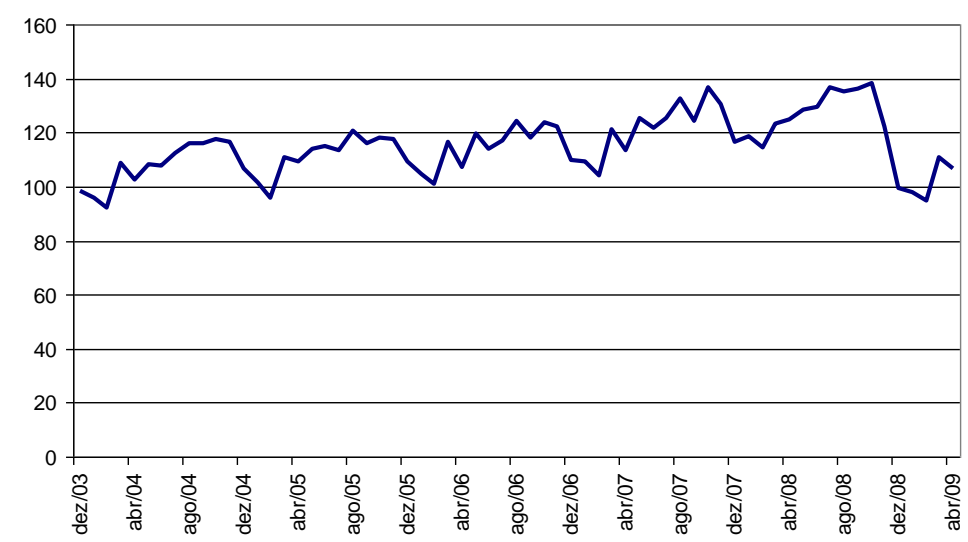

FONTE: Banco Central do Brasil.

Para analisar o comportamento de curto-prazo da SELIC, sem restrição do problema da "caderneta de poupança", rodamos modelos de Vetores Auto-Regressivos (VAR) com as seguintes variáveis: SELIC, IPCA, CÂMBIO, MOEDA e PIB. Conforme a Tabela 1, o modelo VAR prevê a continuidade da flexibilização da política monetária. O

${ }^{23}$ Caso não exista a redução da remuneração das cadernetas de poupança, hoje em torno de 6,17\% a.a., ou não alterar as condições vigentes das LFT's pode haver uma migração dos investidores de renda fixa tipo "títulos públicos" e "certificados de depósitos" para a poupança. Nesse ponto, o ciclo de queda da Selic poderá ficar restrito, por exemplo, em torno de $8,5 \%$ a $9 \%$ a.a. Isso porque se a SELIC cair abaixo de $9 \%$ a.a., a remuneração dos títulos públicos, descontado taxas e impostos, ficará abaixo da remuneração da caderneta de poupança e, portanto, será menos atrativa. Caso a autoridade monetária resolver o problema rapidamente, a taxa de juros e os títulos públicos continuarão poderosos para controlar a liquidez do sistema financeiro nacional e o banco central terá espaço suficiente e considerável para a continuidade da flexibilização da política monetária. 
comportamento de queda da taxa SELIC deve-se a queda do nível de atividade econômica, inflação abaixo da meta e ao efeito "derretimento" da taxa de câmbio nominal, a qual deverá atingir o patamar de $\mathrm{R} \$ 1,80$ em agosto.

TABELA 1 - PREVISÃO SELIC E CÂMBIO, MODELOS VAR, JUN A SET/2009.

\begin{tabular}{ccc}
\hline & \multicolumn{3}{c}{ Previsões } \\
\hline SELIC & Intervalo de Confiança \\
\hline Jul $/ 09$ & $9,21 \%$ & $9,15 \%<$ juros $<9,27 \%$ \\
Ago $/ 09$ & $8,79 \%$ & $8,53 \%<$ juros $<9,05 \%$ \\
\hline Jun $/ 09$ & $8,07 \%$ & $7,74 \%<$ juros $<8,40 \%$ \\
Jul $/ 09$ & CÂMBIO (R $\$ /$ USD) & Intervalo de Confiança \\
Ago/09 & 1,92 & $1,82<$ câmbio $<2,02$ \\
& 1,86 & $1,75<$ câmbio $<1,97$ \\
\hline
\end{tabular}

FONTE: Elaboração própria.

Também, pelo VAR (ver Tabela 2), é esperado para dezembro de 2009, queda de 1,3\% do PIB, IPCA abaixo do centro da meta, 3,73\% a.a, Selic em torno de $8 \%$ e câmbio próximo a $\mathrm{R} \$ / \mathrm{USD}=1,70$.

TABELA 2. PREVISÃO SELIC, PIB, CÂMBIO, IPCA, MODELOS VAR, 2009.

\begin{tabular}{ccc}
\hline \multicolumn{2}{c}{ Previsões para Dezembro de 2009} \\
\hline Velic & Valores & Intervalo de Confiança \\
Câmbio & $7,72 \%$ a.a & $7,23 \%<$ juros $<8,21 \%$ \\
IPCA & R $\$$ USD 1,71 & $1,61<$ câmbio $<1,81$ \\
PIB & $3,73 \%$ a.a & $3,49 \%<$ inflação $<3,97 \%$ \\
\hline
\end{tabular}

FONTE: Elaboração própria.

O saldo da Dívida Líquida do Setor Público com Relação ao PIB é outro indicador a ser considerado. A Figura 3 mostra que, desde 2003, a relação Dívida Líquida do Setor Público com Relação ao PIB está caindo. No mais as expectativas de mercado até 2013, conforme Boletim Focus de junho, apontam para a continuidade de tendência do movimento de queda. Para 2009, a expectativa é de 39\% e para 2013 é de 33\%.

Ainda com relação à dívida pública, do total da dívida emitida via títulos públicos federais, apenas em torno de 1\% estão indexadas ao câmbio em 2009, ante aos quase 40\%, em 2002. Portanto, caso o real tiver tendência de depreciar fortemente, o que na conjuntura atual não é o caso (ver Tabelas 1 e 2), a dívida líquida do setor público não sofrerá grandes variações. 
FIGURA 3 - DÍVIDA LÍQUIDA DO SETOR PÚBLICO/PIB.

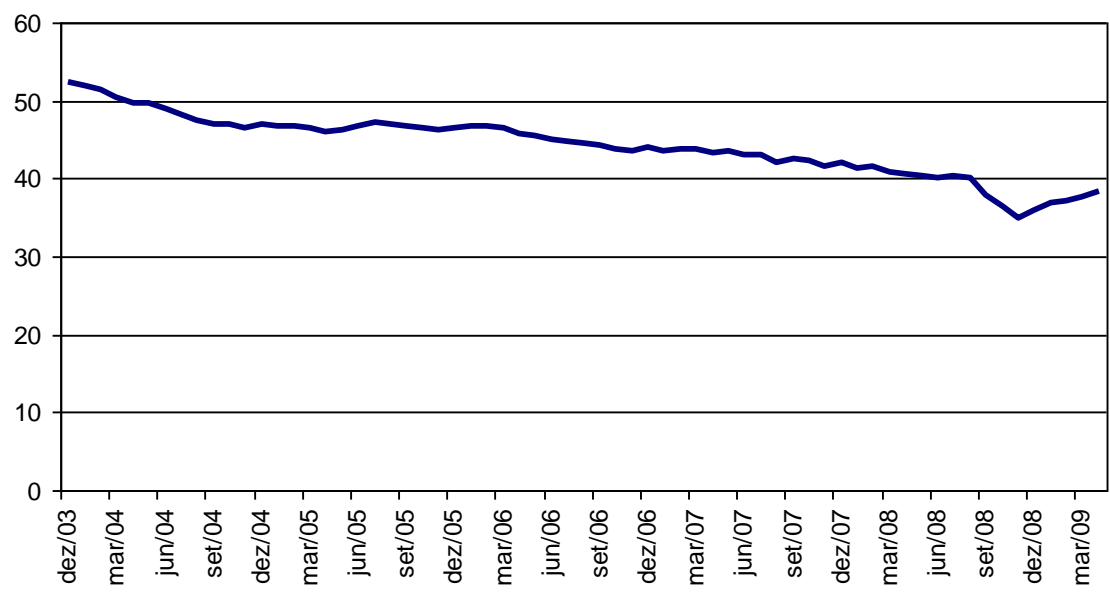

FONTE: Banco Central do Brasil.

Atualmente, pela composição da dívida pública (Figura 4) o ponto de preocupação deve ser a inflação e as taxas de juros. Apesar da atual tendência de queda dos juros e manutenção da inflação dentro da meta, blindar a dívida pública com relação as taxas de juros Selic e inflação, para diminuir o risco sistemático do país, é uma boa alternativa. Nesse sentido, a composição da dívida pública foi alterada significativamente após 2004.

FIGURA 4 - COMPOSIÇÃO DA DÍVIDA LÍQUIDA DO SETOR PÚBLICO 1999-2009

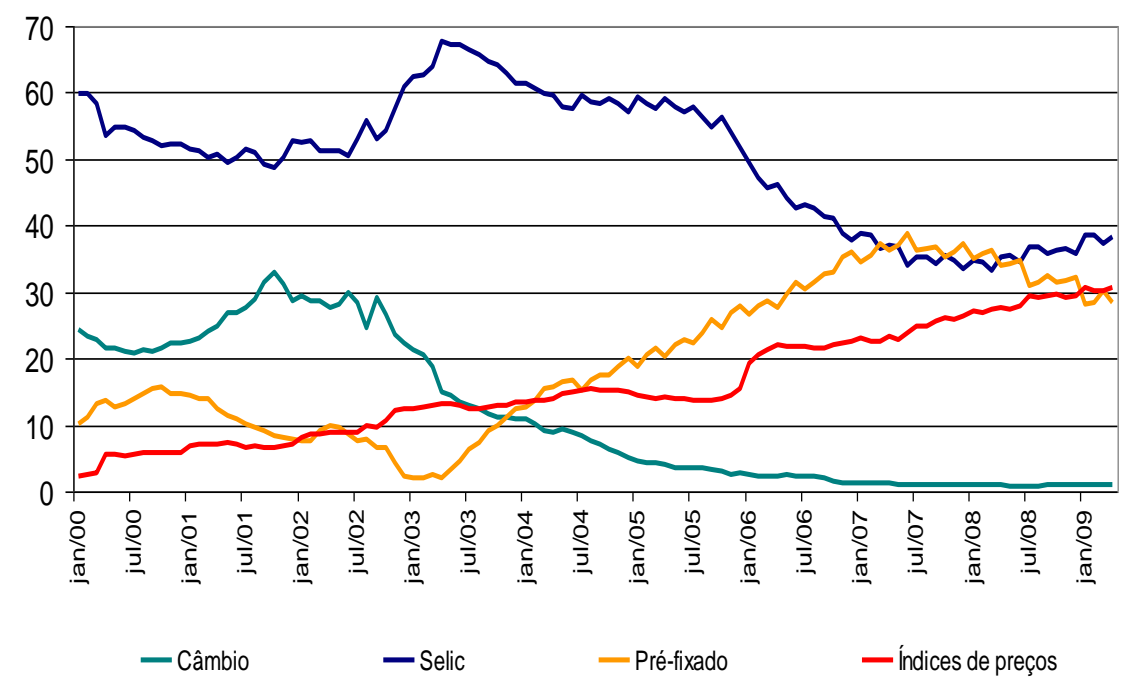

FONTE: Banco Central do Brasil.

O peso da inflação na composição da dívida aumentou. É similar ao peso da taxa de juros e das rentabilidades pré-fixadas, ambas em torno de 30\%. A blindagem pela renda préfixada ajuda o governo a equilibrar a dívida pública, principalmente em horizontes mais longos, caso exista aumentos da Selic e/ou da inflação. Isso contribui para colocar o país numa situação macroeconômica melhor do que em anos anteriores.

60 
No mais, percebe-se, pela Figura 5, que a relação da Dívida Líquida do Setor Público com Relação ao PIB e a Dívida Externa Líquida do Setor Público, ambas as séries mensais, apresentam tendência de queda. De tomador líquido, o Brasil passou a ser credor líquido internacional em $2007^{24}$.

FIGURA 5 - DÍVIDA EXTERNA LÍQUIDA COM RELAÇÃO AO PIB

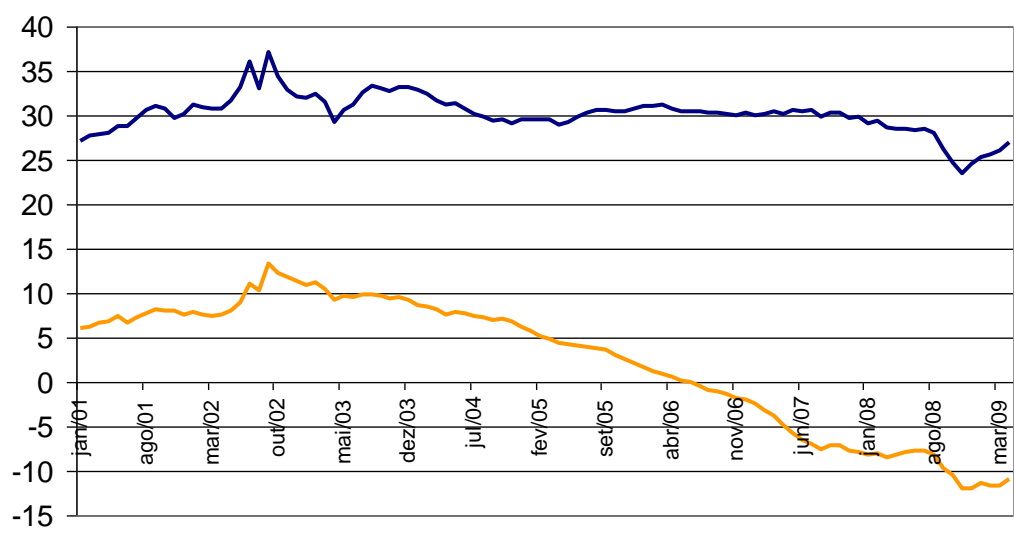

— Dívida Líquida do Setor Público (\% PIB) - Total_ — Dívida Líquida do Setor Público (\% PIB) - Externa

FONTE: Banco Central do Brasil.

Uma blindagem importante em períodos de crises financeiras são as reservas internacionais (Figura 6). Ao longo dos anos percebe-se que as reservas internacionais aumentaram em aproximadamente seis vezes. Com o programa de aumentar as reservas internacionais, ao longo dos últimos anos, o Banco Central do Brasil, sob regime de taxas de câmbio flexíveis, recuperou um instrumento de controle monetário e de liquidez em moeda estrangeira. E ainda, aumentou a potência do Banco Central para realizar intervenções administradas no câmbio.

Com o aumento das reservas, o Banco Central do Brasil está sendo capaz, por exemplo, através de operações de swap, de conter fortes depreciações do real (entre setembro a dezembro) e nos últimos meses conter apreciações mais fortes do real perante o dólar. Mais uma vez, outro indicador, das reservas internacionais, tão importante em períodos de crise, pode ajudar o Brasil a ser um dos primeiros países a sair da recessão.

\footnotetext{
${ }^{24}$ Sinal negativo na relação Dívida Líquida do Setor Público com Relação ao PIB significa que o Brasil é credor internacional líquido.
} 
FIGURA 6 - RESERVAS INTERNACIONAIS DO BRASIL - 2003-2009

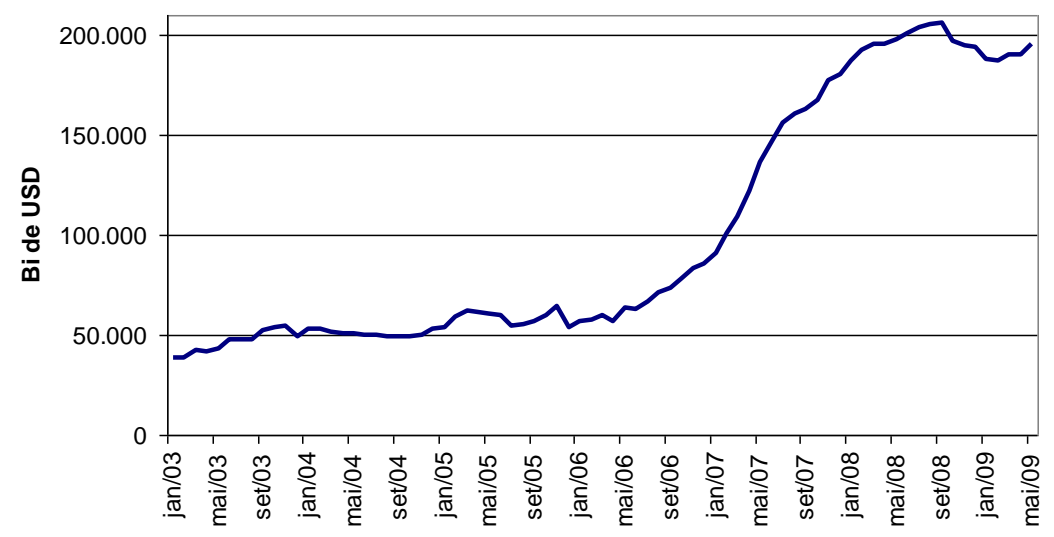

FONTE: Banco Central do Brasil.

Outro ponto importante: a comparação da inflação versus produto (Tabela 3). Após a falência do Lehman Brothers, em setembro de 2008, o Brasil, é um dos países que menos tiveram retração no nível da atividade econômica, em \%, e da inflação acumulada.

Antes, choques externos, deterioravam muito a confiança do país em relação às outras praças do mercado financeiro internacional. Ao longo do tempo, com o aumento das reservas internacionais, a queda da dívida líquida do setor público com relação ao PIB, a melhor composição da dívida pública, a insignificante participação do câmbio na composição da dívida, o cumprimento das metas de inflação, o país na condição de credor internacional líquido, o ciclo atual de queda das taxas de juros, faz com que o Brasil tenha uma expectativa positiva e otimista quanto à saída mais rápida recessão. 
TABELA 3 - PRODUÇÃO INDUSTRIAL E INFLAÇÃO ACUMULADA, PAÍSES SELECIONADOS.

\begin{tabular}{|c|c|c|c|c|c|c|c|c|}
\hline \multicolumn{9}{|c|}{ Produção Industrial, em \% } \\
\hline Período & USA & $\mathrm{EU}$ & JPN & CHINA & RUSSIA & INDIA & TURQUIA & BRASIL \\
\hline Set/08 & -6.2 & $-3,2$ & 0,2 & 11,4 & 6,4 & 6,2 & $-4,3$ & 9,7 \\
\hline Out/08 & $-4,3$ & $-5,8$ & $-7,1$ & 8,2 & 1,7 & $-0,6$ & $-6,7$ & 1,1 \\
\hline Nov/08 & $-5,9$ & $-8,3$ & $-16,6$ & 5,4 & $-8,7$ & 2,6 & $-13,2$ & $-6,4$ \\
\hline Dez/08 & $-8,2$ & $-12,4$ & $-20,8$ & 5,7 & $-10,3$ & $-1,1$ & $-17,8$ & $-14,8$ \\
\hline Jan/09 & $-10,1$ & $-15,7$ & -31 & 3,8 & -16 & 0,3 & $-21,4$ & $-17,4$ \\
\hline Fev/09 & $-11,2$ & $-18,4$ & $-38,4$ & 3,8 & $-13,2$ & $-1,4$ & $-23,7$ & -10 \\
\hline Mar/09 & $-12,5$ & $-16,2$ & $-34,2$ & 8,3 & $-13,7$ & $-1,2$ & - & $-4,3$ \\
\hline \multicolumn{9}{|c|}{ Inflação Acumulada, em \% } \\
\hline Set/08 & 4,9 & 3,6 & 2,1 & 4,6 & 15 & 9,8 & 11,1 & 6,3 \\
\hline Out/08 & 3,7 & 3,2 & 1,7 & 4,0 & 14,2 & 10,4 & 12,0 & 6,4 \\
\hline Nov/08 & 1,1 & 2,1 & 1,0 & 2,4 & 13,8 & 10,4 & 10,8 & 6,4 \\
\hline Dez/08 & 0,1 & 1,6 & 0,4 & 1,2 & 13,3 & 9,7 & 10,1 & 5,9 \\
\hline Jan/09 & 0 & 1,1 & 0 & 1,0 & 13,4 & 10,4 & 9,5 & 5,8 \\
\hline Fev/09 & 0,1 & 1,2 & $-0,1$ & $-1,6$ & 14,0 & 9,6 & 7,7 & 5,9 \\
\hline Mar/09 & 0,2 & 0,6 & $-0,3$ & $-1,2$ & 13,2 & 8,0 & 7,9 & 5,6 \\
\hline Set/Mar em p.p & $-5,3$ & $-3,0$ & $-2,4$ & $-5,8$ & $-1,0$ & $-1,7$ & $-3,2$ & $-0,6$ \\
\hline
\end{tabular}

FONTE: Bloomberg.

\section{REFERÊNCIAS}

BANCO CENTRAL DO BRASIL. Boletim Focus, diversos números. Disponível em http://www.bcb.gov.br/?FOCUS . Acesso em: 10/12/2009.

BLOOMBERG. Dados de Expectativas. Disponível em http://www.bloomberg.com/news/economy. Acesso em: 07/006/2009.

MEIRELLES, H. O Brasil diante da Crise: Estabilidade e Resistência. Apresentação na reunião do Conselho de Desenvolvimento Econômico e Social (CDES), março. 2009. Disponível em http://www.bcb.gov.br/noticias/Noticias.asp?noticia=1\&idioma=P. Acesso em: 08/06/2009.

MESQUITA, M. Brazil: Economic Prospects. Disponível em

Http://www.bcb.gov.br/noticias/ Noticias.asp? noticia=1\&idioma=P. Acesso em: 08/06/2009. 
